\title{
Sexual Dimorphism on Shell Shape of Pomacea canaliculata Lamarck Thriving in Lakes Using the Geometric Morphometric Approach
}

\author{
Jhun Joules M. Mahilum and Cesar G. Demayo
}

\begin{abstract}
Several studies have shown different interpretations about shell shape variation and sexual dimorphism on Pomacea canaliculata Lamarck. This study, however, was conducted to evaluate and determine the existence of sexual dimorphism and shape variation in the shells of golden apple snails by using landmark-based analysis in its dorsal and ventral/apertural portion and using geometric morphometric approach. Results have shown significant variations validated by relative warp analysis and Canonical Variation Analysis. Moreover, Discriminant Function Analysis and Cluster Analysis also showed significant shell shape variation between sexes proving the occurrence of sexual dimorphism within species of golden apple snails obtained from lakes.
\end{abstract}

Index Terms-Golden apple snails, Pomacea canaliculata, sexual dimorphism, shell shape variation.

\section{INTRODUCTION}

The golden apple snail, Pomacea canaliculata (Lamarck, 1822) was intentionally introduced in the Philippines from South America as an alternative protein supplement. However, because of its short maturation time (2-3 mos.) and its potential to lay large numbers of eggs [1], [2], $P$. canaliculata remains to have a growing populations on freshwater habitats and eventually has become an important pest on rice. The golden apple snails in the Philippines show wide variability in shell shape and the observations of shell shape variation in many populations, which make this species a good model to solve the issue of its succession as pest and its evolution as an organism.

Studies on describing the organism's body shapes have progressed from traditional qualitative approach into quantitative approach using different effective methods. In this study, the researchers examined the shell shape by employing the newly developed methodological and analytical tool, computer software, which is able to facilitate data by acquiring, interpreting, and presenting the shape data collectively, known as geometric morphometric (GM) techniques. Analysis of shape differences both in intra- and interspecific populations was solely based on anatomical landmarks defined by Cartesian coordinates (X and $\mathrm{Y}$ )

Manuscript received February 23, 2014; revised May 6, 2014. This work was funded by the Department of Science and Technology - (SEI) ASTHRDP

The authors are with the Department of Biological Sciences, College of Science and Mathematics, MSU-Iligan Institute of Technology, Andres Bonifacio Avenue, Tibanga, Iligan City, Lanao del Norte, Philippines (e-mail: joulesmahilum@gmail.com, cgdemayo@gmail.com). acquired and defined from joint image analysis and geometic morphometric data. This type of method using shell shape can be useful in presenting the taxonomic difference between the sexes of golden apple snail. This difference was found not only in wide geographical locations but also in small scale geographical difference and more on isolated populations with minimal selection pressures and competitions such as those in lakes. Using shell morphology, several studies accounting for shell variability between male and female $P$. canaliculata. [3]-[6] state that there was a general tendency that the shell's shape for each sex of $P$. canaliculata cluster together suggesting that there was a sexual dimorphism. Despite conflicting environments, $P$. canaliculata proved to have high phenotypic plasticity scale on both morphological and biological structures which have high variability and adaptability to varied variation in the environment [6], [7]. Moreover, microgeographic difference, even in small scale geographical pattern, still proved that there is a variation in shell shape of this species [8]. With this information, the main objective of this study was to examine, describe and understand the shell shape variation of $P$. canaliculata collected from different lakes found in Mindanao, Philippines. This research was carried out to examine the shell shape variations using geometric morphometric approach through relative warp analysis. The information acquired can be useful to conduct future studies on molecular approach and to eventually create appropriate pest control with regards to the species studied.

\section{Materials AND Methods}

The golden apple snails (Pomacea canaliculata) were obtained from three lakes in Mindanao, Philippines (Lake Lanao, Lake Dapao and Lake Wood) (Fig. 1). A total of 180 samples were collected, each comprising 30 males and 30 females per population.

The shells were boiled with water and then cleaned with tap water after the meat was removed with a pin. Shells with cracks and eroded spires were discarded. The images of the shells were captured by using a DSLR camera, Nikon D5100. The shells were oriented in such a way that the spire was at $90^{\circ}$ of the $\mathrm{x}$-axis in a $2 \mathrm{D}$ orientation with the ventral side of the shell facing the top. All shells were captured in the same position. The camera, with constant $55 \mathrm{~mm}$ focal length, was mounted on a tripod to maintain a constant distance from the top of the shell and in order to obtain good images to minimize measurement error.

Landmark-based methodology was used to study the shell shape of $P$. canaliculata which was automatically 
transformed all 2D coordinates determined for each shell specimen into Procrustes average configuration. As previously defined by [5], Seventeen (17) anatomical landmarks located along the outline of the dorsal (Fig. 2a) portion of the shell and twenty-one anatomical landmarks located along the outline of ventral/apertural (Fig. 2b) portion of the shell were used. The $\mathrm{X}$ and $\mathrm{Y}$ coordinates were outlined with landmark points along the contour of the shell into the obtained images. This was accomplished by using image analysis and processing software Tps Dig freeware 2.12. Tps.Dig facilitated the statistical analysis of landmark data in morphometric by making it easier to collect and maintain landmark data from digitized images [9]. Relative warps analysis was performed using tpsRelw version 1.48 [10]. Then, the generalized orthogonal least squares Procrustes average configuration of landmarks was computed using the Generalized Procustes Analysis (GPA) superimposition method. GPA was performed using the software tpsRelw, ver. 1.48 [10]. After GPA, the relative warps (RWs, which are the principal components of the covariance matrix of the partial warp scores) were computed using the unit centroid size as the alignment-scaling method [11], [12]. The relative warp scores from 2D coordinates were then transferred to Microsoft Excel application for the organization of the data into groups (based on shell portions and eventually segregated into male and female).

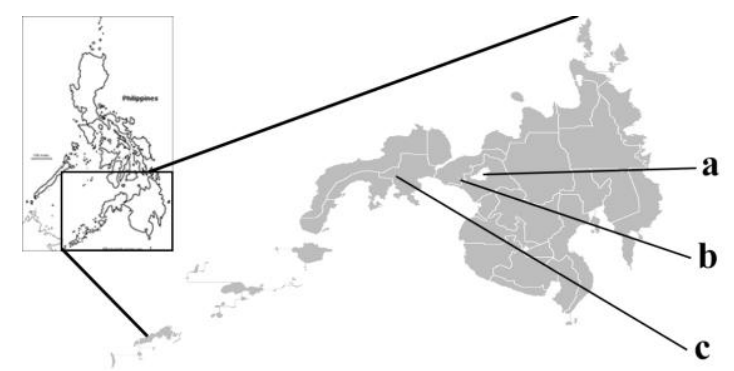

Fig. 1. Map locating the study areas a) Lake Lanao, Lanao del Sur, b) Lake Dapao, Lanao del Sur and c) Lakewood, Zamboanga del Sur.

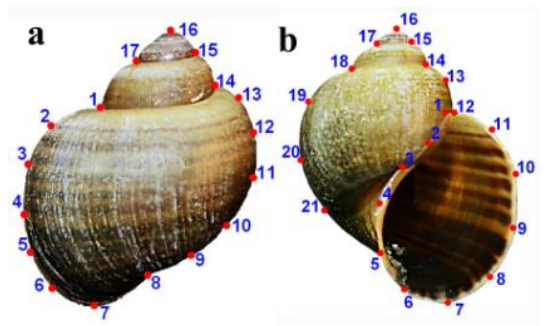

Fig. 2. Landmark used to describe the shape of a) dorsal and b) ventral/apertural view of the shell of $P$. canaliculata.

Data analysis, such as histogram and box plots of significant warp scores, Canonical Variance Analysis (CVA), MANOVA, Cluster Analysis, Kruskal-Wallis Test and Discriminant Function Analysis/Hotelling's Test were carried out by using Paleontological Statistics (PAST) Software version 2.17c [13]. Histogram and boxplots were effective in displaying for comparison distributions. CVA was also used to map in a scatter plot in order to compare patterns of variation in population level. Cluster analysis was useful in showing a tree that automatically groups the most correlated species, group or population. Differences in shell shapes of GAS between sexes were analyzed using
Kruskal-Wallis Test. Discriminant Function Analysis/Hotelling's Test was also carried out to show whether the sexual dimorphism based on the shell shape (ventral/apertural, dorsal) pattern was statistically significant.

\section{RESUlTS AND DISCUSSION}

The summary of the geometric morphometric analysis showing the centroid/mean morphology and variation in the dorsal and ventral/apertural shell shape pattern of different $P$. canaliculata populations as produced by the relative warps (RW) is shown in Fig. 3 and described in Table I. Projections on the left side of the histogram are considered to be variations in shell shape expected as negative deviations of the mean in the axis of the relative warps. Then, on the right side are variations in shell shape expected as positive deviations of the mean in the axis of the relative warps. The topmost figure is the mean shape of the samples. Differences between sexes and geographical regions are based on the results of the Kruskal-Wallis test shown in Table II (dorsal) and Table III (ventral/aperture).

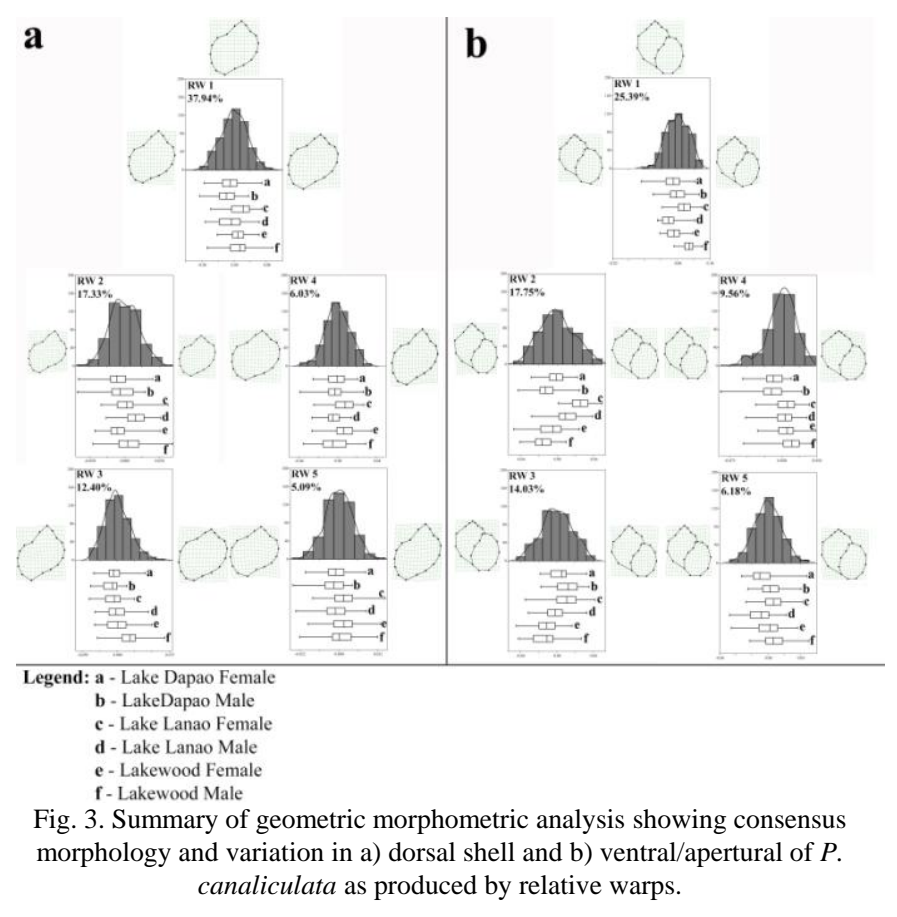

Results of the Kruskal-Wallis Test from Table II and Table III show the differences between sexes in each population. These results support the description of the samples where variation on shell shape of $P$. canaliculata can be observed. According to [6], snail's plasticity has focused either on presence or absence of a single factor, or has looked at responses to environmental gradients over large geographical scales. However, findings in this study show only a little variation despite the far geographical location. Samples were obtained from lakes, consequently snails possess only minimal variation. This can be due to the reason where they only have minimal selection pressures and competitions. Shell shape remains distinguishable when snails from unrelated sources are reared under homogenous laboratory conditions, which is a strong indication of a genetic basis for the observed differences [14]. There must be a genetic basis that can be attributed from the observed differences. 


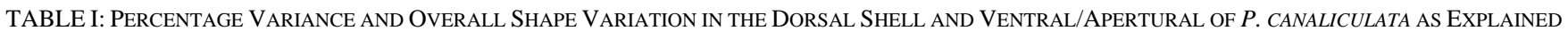
BY SIGNIFICANT RELATIVE WARPS

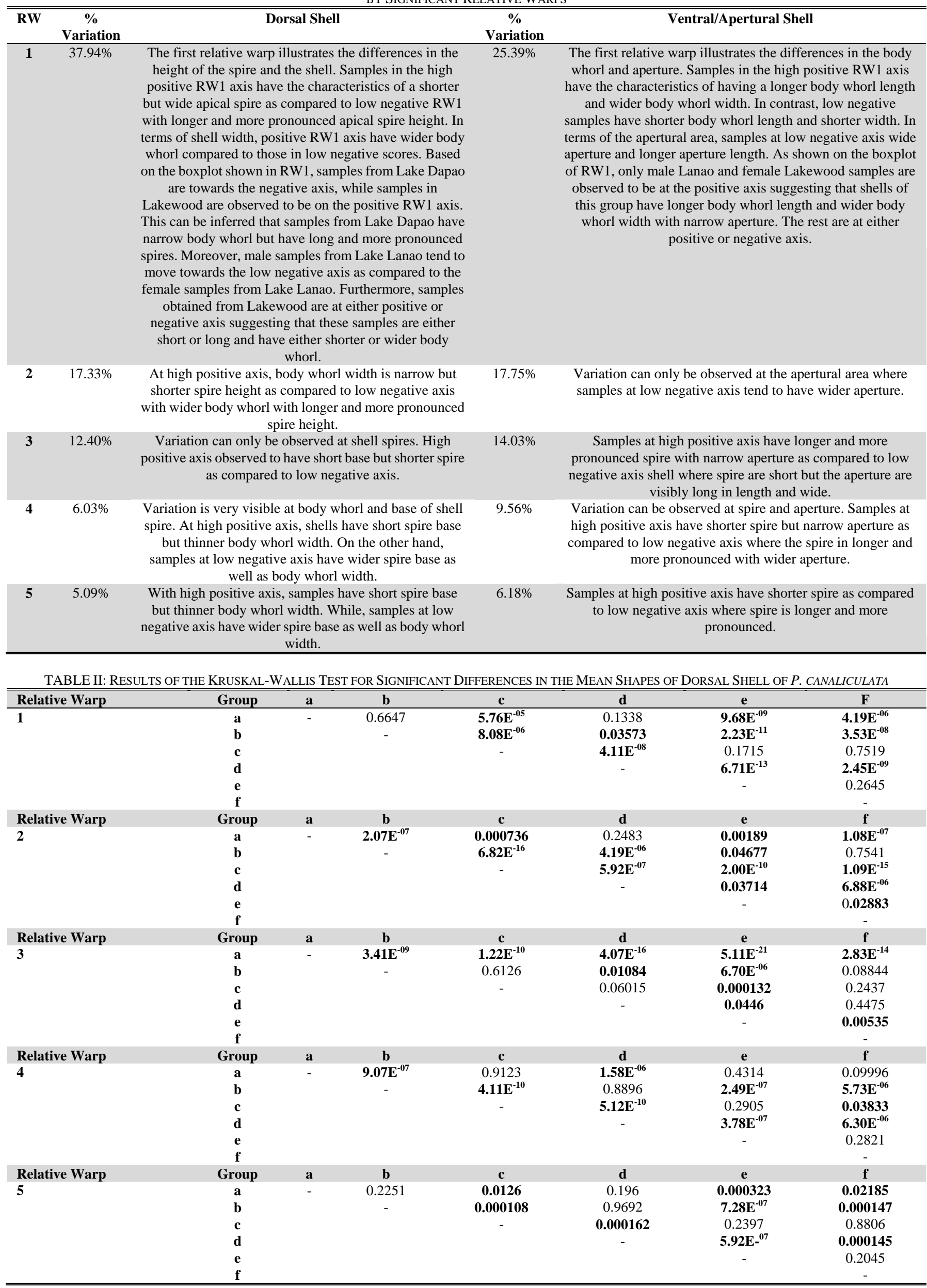


TABLE III: RESULTS OF THE KRUSKAL-WALLIS TEST FOR SigNIFICANT DifFERENCES IN THE MEAN SHAPES OF VENTRAL/APERTURAL SHELL

\begin{tabular}{|c|c|c|c|c|c|c|c|}
\hline Relative Warp & Group & 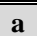 & $\overline{\mathbf{b}}$ & 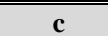 & $\bar{~} \bar{d}$ & 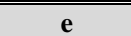 & $\overline{f(f}$ \\
\hline \multirow[t]{6}{*}{1} & $\mathbf{a}$ & - & $1.23 E^{-24}$ & $2.98 \mathrm{E}^{-25}$ & $1.82 E^{-04}$ & $1.41 \mathrm{E}^{-15}$ & $7.32 \mathrm{E}^{-20}$ \\
\hline & b & & - & 0.00016 & $2.36 \mathrm{E}^{-15}$ & 0.002603 & 0.4824 \\
\hline & c & & & - & $3.78 E^{-19}$ & $1.12 E^{-08}$ & 0.03269 \\
\hline & d & & & & - & $9.83 E^{-07}$ & $2.67 \mathrm{E}^{-12}$ \\
\hline & e & & & & & - & 0.003891 \\
\hline & $\mathbf{f}$ & & & & & & - \\
\hline Relative Warp & Group & $\mathbf{a}$ & b & c & d & e & $\mathbf{F}$ \\
\hline \multirow[t]{6}{*}{2} & $\mathbf{a}$ & - & $6.78 E^{-05}$ & $5.93 E^{-23}$ & $2.40 \mathrm{E}^{-30}$ & 0.1032 & $1.68 \mathrm{E}^{-12}$ \\
\hline & b & & - & $1.69 \mathrm{E}^{-13}$ & $1.35 \mathrm{E}^{-27}$ & 0.007765 & 0.003633 \\
\hline & c & & & - & $3.16 \mathrm{E}^{-11}$ & $5.58 \mathrm{E}^{-20}$ & $1.01 E^{-07}$ \\
\hline & d & & & & - & $5.16 \mathrm{E}^{-29}$ & $2.50 \mathrm{E}^{-23}$ \\
\hline & e & & & & & - & $4.72 \mathrm{E}^{-09}$ \\
\hline & $\mathbf{f}$ & & & & & & - \\
\hline Relative Warp & Group & $\mathbf{a}$ & b & c & d & e & $\mathbf{f}$ \\
\hline \multirow[t]{6}{*}{3} & a & - & 0.4157 & $2.53 \mathrm{E}^{-07}$ & $1.12 E^{-16}$ & $2.53 \mathrm{E}^{-19}$ & $1.74 \mathrm{E}^{-13}$ \\
\hline & b & & - & $9.17 \mathrm{E}^{-06}$ & $3.45 \mathrm{E}^{-15}$ & $7.03 \mathrm{E}^{-18}$ & $5.88 \mathrm{E}-{ }^{12}$ \\
\hline & c & & & - & $3.96 E^{-07}$ & $7.64 E^{-09}$ & 0.00213 \\
\hline & d & & & & - & 0.5281 & 0.002161 \\
\hline & e & & & & & - & 0.000457 \\
\hline & f & & & & & & - \\
\hline Relative Warp & Group & $\mathbf{a}$ & b & c & d & e & $\mathbf{f}$ \\
\hline \multirow[t]{6}{*}{4} & a & - & 0.007864 & $3.25 \mathrm{E}^{-05}$ & 0.01148 & $6.44 E^{-16}$ & $1.12 \mathrm{E}^{-18}$ \\
\hline & b & & - & 0.1335 & 0.9749 & $1.11 \mathrm{E}^{-11}$ & $2.29 \mathrm{E}^{-14}$ \\
\hline & c & & & - & 0.114 & $7.90 \mathrm{E}^{-09}$ & $1.67 \mathrm{E}^{-10}$ \\
\hline & d & & & & - & $9.35 \mathrm{E}^{-12}$ & $1.04 \mathrm{E}^{-13}$ \\
\hline & e & & & & & - & 0.9123 \\
\hline & $\mathbf{f}$ & & & & & & - \\
\hline Relative Warp & Group & $\mathbf{a}$ & b & c & d & e & f \\
\hline \multirow[t]{6}{*}{5} & a & - & 0.006889 & $5.18 \mathrm{E}^{-12}$ & 0.5508 & 0.05748 & $2.05 \mathrm{E}^{-11}$ \\
\hline & b & & - & $4.55 \mathrm{E}^{-06}$ & 0.03317 & 0.3547 & $3.54 \mathrm{E}^{-05}$ \\
\hline & c & & & - & $5.97 \mathrm{E}^{-11}$ & $1.20 \mathrm{E}^{-08}$ & 0.4059 \\
\hline & d & & & & - & 0.1666 & $7.20 \mathrm{E}-{ }^{10}$ \\
\hline & e & & & & & - & $1.28 E-{ }^{07}$ \\
\hline & f & & & & & & - \\
\hline
\end{tabular}

Where: a - Lake Dapao Female; b - Lake Dapao Male; c - Lake Lanao Female; d - Lake Lanao Male; e - Lakewood Female; f - Lakewood Male

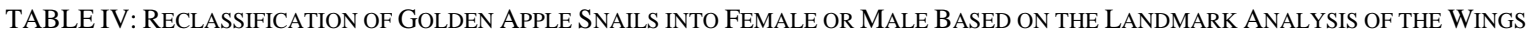

\begin{tabular}{|c|c|c|c|c|}
\hline Dorsal & & Female & Male & Total \\
\hline \multirow{3}{*}{ Lake Dapao } & Female & 72 & 18 & 90 \\
\hline & Male & 18 & 72 & 90 \\
\hline & \% Correctly Classified & & & $88 \%$ \\
\hline \multirow{4}{*}{ Lake Lanao } & Female & 80 & 10 & 90 \\
\hline & Male & 19 & 71 & 90 \\
\hline & $\%$ Correctly Classified & & & $\mathbf{8 3 . 8 9 \%}$ \\
\hline & Female & 54 & 36 & 90 \\
\hline \multirow[t]{2}{*}{ Lakewood } & Male & 36 & 54 & 90 \\
\hline & \% Correctly Classified & & & $60 \%$ \\
\hline \multirow[t]{2}{*}{ Ventral } & & Female & Male & Total \\
\hline & Female & 82 & 8 & 90 \\
\hline \multirow{3}{*}{ Lake Dapao } & Male & 4 & 86 & 90 \\
\hline & $\%$ Correctly Classified & & & $93.33 \%$ \\
\hline & Female & 86 & 4 & 90 \\
\hline \multirow[t]{3}{*}{ Lake Lanao } & Male & 6 & 84 & 90 \\
\hline & $\%$ Correctly Classified & & & $\mathbf{9 4 . 4 4 \%}$ \\
\hline & Female & 77 & 13 & 90 \\
\hline \multirow{2}{*}{ Lakewood } & Male & 18 & 72 & 90 \\
\hline & $\%$ Correctly Classified & & & $82.78 \%$ \\
\hline
\end{tabular}

The CVA scatter plot in Fig. 4 shows the distribution of female and male $P$. canaliculata per population based on the landmark analysis. CVA scatter plots were obtained from pooled individuals from different populations which displayed patterns of geographical variation. Results of the Multivariate Analysis of Variance (MANOVA) for the dorsal portion of the shell obtained $p$-values of $7.47 \mathrm{E}^{-17}$ and $7.029 \mathrm{E}^{-16}$ for female and male populations of $P$. canaliculata, respectively. The ventral/aperture portion of the shell obtained $p$-values of $3.715 \mathrm{E}^{-85}$ and $1.267 \mathrm{E}^{-16}$ for female and male populations of $P$. canaliculata, respectively.

Table IV shows the results of the discriminant analysis indicating that the male and female sexes were correctly classified and statistically significant. Fig. 5 shows discriminant histogram on dorsal portion of the $P$. canaliculata specimen from Lake Dapao and Lake Lanao and this has percent correctly classified with $88 \%$ and $83.89 \%$ respectively. Discriminant histogram on dorsal portion of the shell obtained from Lakewood can be observed to have no sexual dimorphism between sexes from this population. For the ventral portion of the shell, all locations, Lake Dapao, Lake Lanao and Lakewood have percent correctly classified of $93.33 \%, 94.44 \%$ and $82.78 \%$ respectively. The shell shape pattern between male and female on the ventral portion of the shell for all locations can be observed as statistically significant indicating that there was a minimal sexual 
dimorphism in the ventral shape of the shell.

For the hierarchical clustering methods, the dendogram is the main graphical tool for getting insight into a cluster solution. Cluster analysis shows that the majority of the populations in terms of sex are located away from each other. Fig. 6 shows the relationship between populations of male and female $P$. canaliculata.

In Fig. 6, both dorsal (6-a) and ventral (6-b) show that the cluster diagram were divided into three groups according to the similarities shell shape and structure. The distances within locations have higher similarities of their morphometry. On the other hand, Fig. 6-a shows that the populations of pooled dorsal portion of the shell of males were closely related from different locations. This is similar to Fig. 6-b, where males can be observed as being grouped together indicating that they are closely related to each other although belonging to different locations. Moreover, Fig. 6, among populations, show that is a simplicifolious clade for both dorsal and ventral that is, female population from Lakewood and female population from Lake Dapao respectively. Among populations of pooled dorsal portion of the shell (Fig. 6-a), Lakewood male population correlated and grouped closely with male populations from Lake Lanao and Lake Dapao. While among populations of pooled ventral portiong of the shell (Fig. 6-b), Lake Lanao male population correlated and grouped closely with male populations from Lakewood and Lake Dapao. As also shown in Fig. 6-a, the population of female $P$. canaliculata from Lake Lanao was closely related to that of Lake Dapao whereas in Fig. 6-b, the population of female $P$. canaliculata from Lakewood was closely related to that of Lake Lanao. a 우

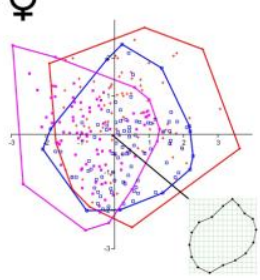

a
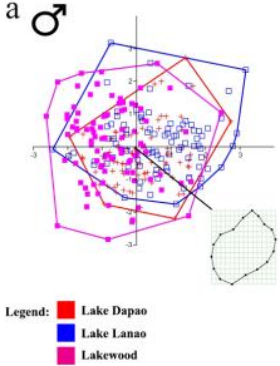

Fig. 4. CVA scatter plot of the a) dorsal and b) ventral/aperture shell of the $P$. canaliculata showing the female $(+)$ and male $\left({ }^{\lambda}\right)$ individuals.

Summarizing all the results, it can deduced that the populations of golden apple snails thriving in lakes showed variations in shell shape as well as in minimal sexual dimorphism in shell morphometry that can be attributed to the unparalleled success of $P$. canaliculata populations. Thus, one should not rely on the influence of environmental conditions in concluding differences in shell shape of $P$. canaliculata. Shell shape, however, as with any other phenotype, is a product of the interaction between the genetic architecture of the individual and the environment [15], [16] concluded that environmentally-based variation of shell shape overrides the genetically-based variation that will result from isolation or genetic drift resulting to widely overlapping ecophenotypic morphs that show an almost continuous variation. However, a study on sex-determining genes without any environmental effects of $P$. canaliculata suggests a more complex system, such as sex-ratio or sex-determining polygenes that act nonadditively [17].

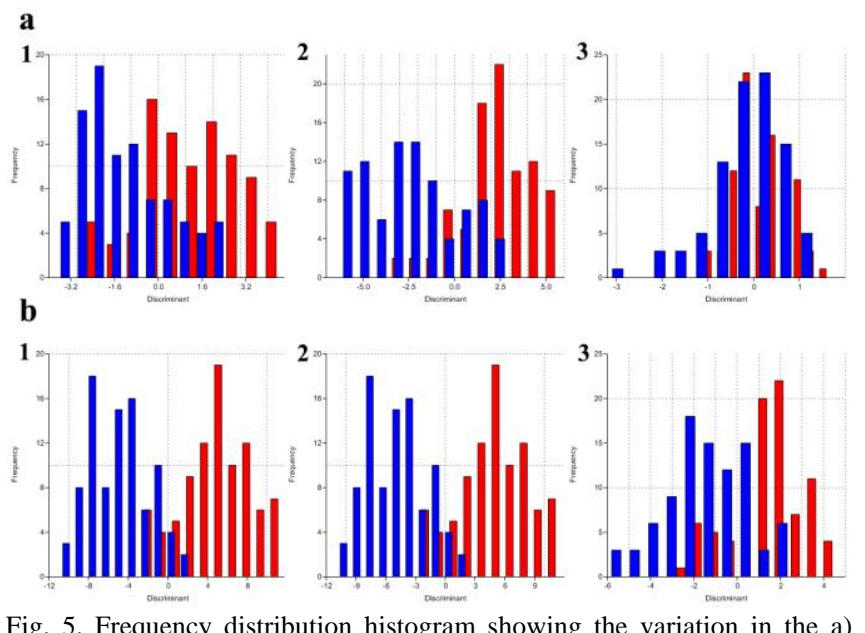
dorsal portion, b) ventral/apertural portion in the shell pattern of female (red) and male (blue) from 1) Lake Dapao, 2) Lake Lanao and 3) Lakewood P.canaliculata populations.
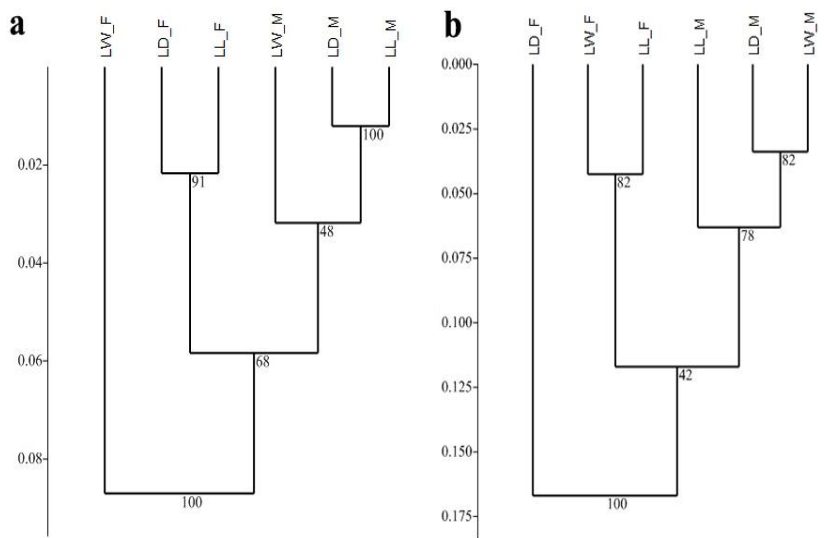

Fig. 6. Cluster diagram based on the morphology scores showing the systematic relationship of Pomacea canaliculata population of dorsal (A) and ventral (B) portion of the shell collected from three lakes in Mindanao, Philippines.

Hence, the application of geometric morphometric approach, in this study, effectively unravels the variation on shell shape of golden apple snails. In addition, geometric morphometric approaches have superior advantage over traditional morphometry in the evaluation of shape variables [18].

These results clearly show that geography really affects the differences in the shell shape of $P$. canaliculata. Moreover, results also showed that there is a variation in the characteristics between male and female shell shape pattern which are geographically closed populations or even those of same location that showed greater differences on their shell shape. It can be hypothesized that variations in the shell shape can be due to isolated locations where there is less to no selection pressures and competition of golden apple snails thriving in lakes. This unparalleled success of $P$. canaliculata 
thriving in lakes is a very important threat to other native and endemic species located on specific lakes in Mindanao, Philippines.

\section{CONCLUSION}

Succeeding a series of geometric morphometric analysis made in the shell of $P$. canaliculata Lamarck, it was found out that variations exist in shape of dorsal and ventral portions of the shell between male and female individuals based on landmark-based analysis. Thus, suggesting the presence of shell shape sexual dimorphism within the populations were collected from lakes. This study, therefore demonstrates the efficacy of geometric morphometric methods in describing morphological variation. The uncontrollable variation existing on this species $(P$. canaliculata) could have been affected by its successful selection and accustom to the wide types of environment. Thus, further investigation is recommended in order to determine shape variation and sexual dimorphism in golden apple snails.

\section{ACKNOWLEDGMENT}

The author would like to acknowledge the Department of Science and Technology (DOST) - ASTHRDP for the funding of the research, to Ms. Conaida G. Camama and family for the accompaniment and safety during the collection of samples, and to Michael Muhmin E. Manting for the technical assistance.

\section{REFERENCES}

[1] R. H. Cowie, "Apple snails as agricultural pests: Their biology impact and management," in Mollusca as Crop Pests, G. M. Barker, (ed.), pp. 145-192, Wallingford, UK: CAB International, 2002.

[2] B. Thaewnon-ngiw, S. Klinbunga, K. Phanwichien, N. Sangduen, N. Lauhachinda, and P. Menasveta, "Genetic diversity and molecular markers in introduced and Thai native apple snails (Pomacea and Pila)," Journal of Biochemistry and Molecular Biology, vol. 37, no. 4, pp. 493-502, 2004.

[3] S. R. Tabugo, M. A. J. Torres, and C. G. Demayo, "Relative warps and correlation analysis based on distances shape of the morphological shell of the golden apple snail Pomacea canaliculata from ligan city, Philippines," presented at 2010 International Conference on Environmental Engineeting ond Applications, ICEEA Press, 2010.

[4] C. S. O. Moneva, M. A. J. Torres, and C. G. Demayo, "Sexual Dimorphism in the Shell Shape of the Golden Apple Snail, Pomacea canaliculata (Lamarck) Using Geometric Morphometric Analysis," Egypt. Acad. J. Biolog. Sci., vol. 4, no. 1, pp. 39-46, 2012.

[5] C. S. O. Moneva, M. A. J. Torres, T. Wada, R. C. Joshi, and C. G. Demayo, "Relative warp and correlation analysis based on distances of the morphological shell shape patterns of Pomacea canaliculata lamarck from Japan and the Philippines," Advances in Environmental Sciences, vol. 4, no. 1, pp. 12-21, 2012.
[6] M. A. J. Torres, E. O. Cabahug, R. C. Joshi, Z. G. Baoanan, and C. G. Demayo, "Variability in populations of golden apple snail, Pomacea canaliculata,(Lamarck, 1822) in selected locations from The Philippines," Res. J. Recent Sci., vol. 2, no. 8, pp. 12-19, 2013.

[7] N. J. Cazzaniga, "Old species and new concepts in the taxonomy of Pomacea (Gastropoda, Ampullaridae)," Biocell, vol. 26, pp. 71-81, 2002.

[8] K. K. H. Balbosa, M. A. J. Torres, and C. G. Demayo, "Microgeographic Differentiation in Populations of the Golden Apple Snail, Pomacea canaliculata Lamarck," presented at the Second International Congress on Interdisciplinary Research and Development, Thailand, 2012.

[9] J. F. Rohlf, "tpsDig program,” Ecology and Evolution, SUNY at Stony Brook, 2008.

[10] J. F. Rohlf, "Relative Warps version 1.46. Ecology and Evolution," SUNY at Stony Brook, 2008.

[11] J. A. Walker, "The Ability of geometric morphometric methods to estimate a known covariance matrix," Sytematic biology, vol. 49, pp. 686-696, 2000.

[12] D. C. Adams, D. E. Slice, and F. J. Rohlf, "Geometric morphometrics: Ten years ofprogress following the 'revolution',' Ital. J. Zool., vol. 71, 2004.

[13] Ø. Hammer, D. A. T. Harper, and P. D. Ryan, "PAST version 2.17c: paleontological statistical software package for education and data analysis," Paleontologia Electronica, vol. 4, no. 1, pp. 9, 2013.

[14] N. J. Cazzaniga, "Pomacea canaliculata: Harmless and useless in its natural realm (Argentina)," in R. C. Joshi, L. S. Sebastian (eds.), Global advances in ecology and management of golden apple snails. Science City of Muñoz, Nueva Ecija: Philippine Rice Research Institute, pp. 37-60, 2006

[15] M. A. J. Torres, R. C. Joshi, L. S. Sebastian, and C. G. Demayo, "Geographic phenetic variation in the golden apple snail, Pomacea canaliculata (Ampullariidae) based on geometric approaches to morphometrics," AES Bioflux, vol. 3, no. 3, pp. 243-258, 2011.

[16] A. L. Estebenet, P. R. Martín, and S. Burela, "Conchological variation and its origin in Pomacea canaliculata and other South American Ampullaridae (Gastropoda, Architaenioglossa)," Biocell, vol. 30, no. 2, pp. 329-335, 2006

[17] Y. Yusa, "Genetics of sex-ratio variation inferred from parent-offspring regressions and sib correlations in the apple snail Pomacea canaliculata," Heredity, vol. 96, pp. 100-105, 2006.

[18] R. A. Reyment, Multidimensional Paleobiology, New York: Pergamon Press, 1991.

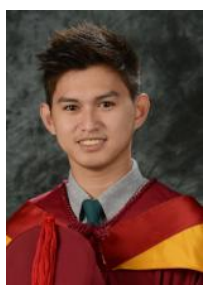

Jhun Joules M. Mahilum is currently pursuing the degree of master of science in biology in the Department of Biological Sciences, College of Science and Mathematics, MSU-Iligan Institute of Technology, Andres Bonifacio Avenue, Tibanga, Iligan City, Lanao del Norte, Philippines.

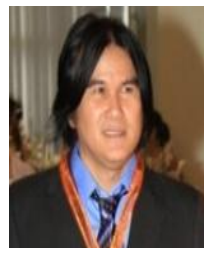

Cesar G. Demayo is the current chairman and professor of the Department of Biological Sciences, College of Science and Mathematics, MSU-Iligan Institute of Technology, Iligan City, Philippines. His researches include environmental toxicology, biodiversity, and genetics. He is an active member of the Philippines Society for the Study of Nature and Pest Management Council of the Philippines. 